\title{
Astronomy Education: Research Paving the Road to Enthusiasm for Studying Science.
}

\author{
Jean-Pierre De Greve \\ Department of Physics, Vrije Universiteit Brussel, \\ Pleinlaan 2, BE-1050 Brussels, Belgium \\ email: jpdgreve@vub.ac.be
}

\begin{abstract}
A brief analysis is given of the need for more trained people in science and technology versus the declined interest in studying sciences. In highlighting some of the aspects of research in astronomy, arguments are presented why astronomy education is by far the most attractive way to stimulate young people to study sciences later on. The availability of vast sets of scientific data with software instruments for instructional use is emphasized. Attention is also given to the changing world of young people, and to the needs and problems in Africa. Finally, some conclusions are given of how astronomy can contribute to transform education in sciences into an education for young people that attracts them towards science \& technology.
\end{abstract}

Keywords. education

\section{Internationally organized astronomy education: what is the IAU doing?}

Let's first turn our attention to internationally organized astronomy education'. What is the IAU presently doing in the area of astronomy education (with new initiatives to come, as we learned from the previous speaker)? The educational activities are concentrated in Commission 46: Education and the public. Its present activities are mostly oriented to research students (post-grad and beyond), much less to lower levels of education, though its mission is much broader: 'The Commission seeks to further the development and improvement of astronomical education at all levels throughout the world, through various projects initiated, maintained, and to be developed by the Commission and by disseminating information concerning astronomy education at all levels."

At present (August 2010), the Commission is composed of 5 Program Groups (PGs):

a. World Wide Development of Astronomy (PGWWDA), responsible: John Hearnshaw.

b. Teaching astronomy for development (TAD), Responsible: Ed Guinan.

c. International Schools for Young Astronomers (ISYAs), responsible: Jean-Pierre De Greve.

d. Network for Astronomy School Education (NASE), responsible: Rosa M. Ros.

e. Commission Newsletter \& Liaisons, responsible: Barrie Jones.

TAD activities will be described by the next speaker (Ed Guinan), so I will only elaborate briefly on the ISYA. But remember that outside the IAU there are countless other initiatives to promote, develop or enhance astronomy education: HOA, the African plan (cf. previous speaker), Olympiads, COSPAR Workshops, local primary and secondary school initiatives, to name just a few. 


\section{The International School of Young Astronomers (ISYA)}

The ISYA is primarily intended for postgraduate students (though it allows sometimes exceptions on either side of the educational phase). What is it and what is it aiming at?

a. Concentrated expert instruction and training in special topics of modern astronomy for those who otherwise would not have such opportunities available.

b. Three weeks, international mix of lecturers, international mix of students

So far, the IAU already organized 32 editions of this program. The next planned ISYAs are:

2011: March 31 till April 20, Yunnan Observatory, China

2012: South African Astronomical Observatory

During recent years a number of novelties were introduced to manage the program and to adapt it to new developments in astronomy: a contract between the IAU and the host institute to describe responsibilities and input of both parties, the use of remote telescopes for the observational part, and the introduction of data mining and processing. Its duration of three weeks allows networking among the participants, interaction with the lecturers and coverage of a broad spectrum of astrophysical topics. Interested future lecturers or organizers can contact me at jpdgreve@vub.ac.be.

\section{Education faces world-wide problems}

Contributing to the overall education from within the particular field of astronomy, is not simply delivering interesting content. It requires knowledge of the medium and long term needs of a specific country, with careful adaptation to the characteristics of the educational system. It also requires an insight into global trans-border problems.

What are the great challenges in the coming decades?

The challenges outside astronomy will come from global changes in the world and major evolutions within society. They are driven by global phenomena such as global warming, ageing of populations, water shortage, and economical shifts in production (Gaudin, 2008). Important challenges that are mentioned in the Gaudin report are the changes resulting from demography, new demographic changes of its own (massive migrations of millions of people, driven by a rise of the sea level and of water shortage, combined with an unequal demographic slow down), the internet penetration, the energy consumption, and the move towards a cognitive civilization. To make my case, I only deal with one of them.

Internet is the most rapidly spreading technology ever. Internet penetration today is quite unevenly spread, but will evolve drastically (numbers between brackets give the expected penetration by 2025 in per cent of the population: Europe 70\%, China 22\% (80\%), Brasil $22 \%(85 \%)$, India $15 \%$ (75\%). In all, it will grow to an average $80 \%$ penetration in 2025. Thus, the "cognitive civilization" will require a new strategy compared to the industrial, technical system. This will drastically affect education, both formal and informal. The new tools of the internet, as well as the new societal goals will force us to renew education on a large scale in the coming decades. 
How does this affect astronomy and its educational contribution?

Astronomy today already has a large and still fast growing web based transborder access to large sets of astronomical data. The astronomical institutes and various foundations develop more and more remote observing equipment and make it also (wholly or partially) available for educational purposes. The astronomical community should consider these capabilities carefully, and in the light of the world-wide fast internet penetration, base its educational strategy on it.

\section{The future need}

Progressing societies with growing economies integrate more and more technology into their societal evolution. This requires an enhancement of competent knowledge workers, specifically in the sciences and applied sciences. That need exists evenly strong on the African continent. Inquiries such as the U.S. Science \& Engineering Indicators (S\&EI, 2010) show that there is a need for S\&E graduates proportionally well above the need for other graduates. Strange enough, the number of young people choosing for scientific studies declines. As Kitts (2009) phrases it: 'They feel they can do science, but they don't want to." The decline of interest in science studies is illustrated by the conclusions from a study of opinions of children in the UK and in the Middle East (Murphy \& Beggs, 2005; Murphy, Ambusaidi and Beggs, 2006):

- end of primary school: $50 \%$ has a sincere interest in science \& technology

- halfway high school: $90 \%$ finds that "studying sciences is not my thing"

We have to ask ourselves why. This is a complex question, involving many parameters. But one of the reasons is that we developed and maintained an educational system that is no longer compatible with the knowledge society, with its needs, and with the opportunities it offers to the young. What do we provide through structured education? We provide scientifically based knowledge, insight and understanding of that knowledge, and the skills to use it.

What do we forget?

Involvement, Engagement, Ownership, Failure (the right to fail).

Teaching scientific knowledge based on research is involving them in the process of discovery, engaging them by the thrill of the problem to solve, provide them ownership over the findings, and give them the right to fail. We teach them the scientific method, so well known and dear to us. But we forget to let them experience an important ingredient of it: failure. A wrong solution, a misinterpretation, the wrong approach or method to solve a differential equation, etc. We experience it every day in our work, but we punish pupils and students for it, or we don't allow it because we haven't time for it in the classroom/curriculum.

\section{Problems for Africa}

But is the above really essential for Africa?

As remarkable as achievements in Science \& Technology education are for other regions of the world, additional challenges and opportunities remain to be met in Africa. 
Indeed, although vital for development, Africa's S\&T education and training infrastructure, particularly in fields such as agriculture and engineering, has been over the years under-valued and under-resourced, as outlined in several reports (cf. SEIA, 2001). The SEIA report states that the neglect of Africa's higher education and technical training institutions over the last four decades has negatively impacted on the capacity of the continent to supply the needed skills base, especially in science and technology. Pressure on governments in Sub-Saharan Africa (SSA) to expand secondary education is growing. Participation rates for secondary education in Sub-Saharan Africa are lower than any region of the world, with access biased in favor of the wealthier populations (SEIA 2001). The lack of access increasingly constrains the countries' abilities to pursue effective economic growth and development strategies. Secondary participation rates in SSA have increased from 19 percent in 1999 to 30 percent in 2004 (SEIA 2007). But some countries, such as Burundi, Burkina Faso, and Rwanda, have not even achieved rates of 20 percent (UNESCO, 2006 as cited in SEIA, 2007).

\section{Building convincing relations with other sciences}

For astronomy, to penetrate stronger into the educational programmes, we need to provide convincing support for the curriculum in a discipline to allow teachers to use it for their benefit. The astronomy contribution to education should offer replacing subject matter in the curriculum, not offering extra material. Teachers have enough to do in limited time. Packages should be constructed both for the teachers and for the programs of teacher training. Maximum use should be made of the fact that the same astronomy topic can be easily and attractively used over different disciplines, and also serves as an ideal project for interdisciplinary teaching. Let me give a two examples (neglecting here the obvious one, i.e. physics):

a. Can astronomy help to make chemistry more interesting for young pupils? There is actually quite a lot of Chemistry used in various areas of Astronomy. Let us try to reverse that. One big application is in the identification of spectral lines. Each element and molecule emits light at very specific frequencies, so we can use this fact to try to identify the composition of astronomical objects from the light they emit. This can be hard, as there will be lots of things mixed in together all emitting different spectral lines (a famous astronomer once tried to reconstruct a piano from the noise it makes as it falls down the stairs!). Areas where chemistry is particularly important is in studies of our Solar System, where the bodies can have very interesting compositions. Another area is looking at Molecular Clouds (clouds with molecules in them) from which it is believed that stars form.

b. In mathematics the opportunities are numerous: derivatives and time behavior of varying star light, or the motion in the sky. But also simple math such as summing and multiplying, where the solar system with its subsets of planets plus satellites can be used. Or statistics where counting the stars in the sky can be a practical project to derive characteristics of a global set through careful sampling data on part of it. Surface or circumference calculations become much more interesting if planets are used instead of abstract spheres.

Astrophysics is especially equipped for inquiry based learning, a very attractive and successful learning method. But the developers and the deliverers of educational packages must make sure that the executed work has an authentic character for each student, that 
he/she is in some way owner of the concrete subjects. Through teamwork and a red line through the tutorial for all teams, an element of group alliance must be created. Instead of linear, the execution of the tutorial must be associative. Then it will be experienced as a challenge. We must use concepts from computer games for the implementation. They have proven to work for young people to keep them attracted to what they're doing, and to let them learn. These concepts are: ownership (implying choice and some autonomy to carry out the project), thrill (by some conditions that imply a certain speed), success and failure (there should be a precise goal that can be reached in different steps similar to the levels in a computer game), membership of a larger community (either by the possibility of sharing data, or by communicating with similar groups in other schools), freedom of activity (part of the project can be done on days and moments chosen by the students, thus stimulating planning), allowance for failure. The overall result will be that the students work harder and with more interest.

\section{Conclusions and suggestions}

What challenges can be derived for all the countries with regards to the changes in the educational system?

a. Internet will become an ingredient. The most successful courses will be available on the Web, enhanced e-learning will penetrate in all curricula.

b. Cooperative learning using the new media will become a common practice.

c. Reversal of roles of theory and practice in instruction, driven by societal demands.

d. New training processes using new didactical approaches (cf computer games).

Astronomical and astrophysical research can indeed participate in, increase its impact, and become an important part of the learning society, as it is a model for inquiry based science education.

To advance in this endeavor, there are two suggestions I would like to end with.

a. The challenge, and at the same time responsibility, for astronomy and astrophysics research is to help attracting young people to science and technology careers as a solid part of the existing educational system. The implementation of astrophysically based tools and packages into the curriculum is possible because its research shows strong characteristics of inquiry based science education.

b. We should try to achieve this through joint, strategically developed efforts (cf The IAU decadal plan, presented by George Miley \& Claude Carignan).

\section{References}

Gaudin, T. 2008, The world in 2025: A challenge to reason, report for DG Research of the European Commission

Kits, K. 2009, J. of Geosci. Ed., 57, 159

Murphy, C. \& Beggs, J. 2005, in: Roth, W-M. \& Tobin, K. (eds.), Teaching together, learning together (New York, NY: Peter Lang), p. 207-231

Murphy, C. ,Ambusaidi, A., \& Beggs, J. 2006, Int. J. of Sci. Ed., p. 405-422

SEIA (2001 ): Secondary Education in Africa 2001, http://siteresources.worldbank.org/AFRICAEXT/ Resources/se_strat_re.htm, visited 6 January 2010 
SEIA (2007): Secondary Education in Africa, Third Regional Conference 2007, http://web.worldbank.org/WBSITE/EXTERNAL/COUNTRIES/AFRICAEXT/ EXTAFRREGTOPEDUCATION/0,,contentMDK:21678070 menuPK:4762583 pagePK:34004173 piPK:34003707 theSitePK:444708,00.html, visited 6 January 2010

S\&EI: Science \&Engineering Indicators pubished by the National Science Board USA 2010, http://www.nsf.gov/statistics/seind10/c3/c3h.htm, visited 6 January 2010 